12 Royal College of Paediatrics and Child Health. Mission, vision and values. April 14, 2014. http://www.rcpch.ac.uk/what-we-do/mission-vision-andvalues/mission-vision-and-values (accessed Aug 1, 2014).

13 Johnson O, Bailey SL, Willott C, et al. Global health learning outcomes for medical students in the UK. Lancet 2012; 379: 2033-35.

14 Suchdev PS, Shah A, Derby KS, et al. A proposed model curriculum in global child health for pediatric residents. Acad Pediatr 2012; 12: 229-37.
15 UNICEF. Convention on the Rights of the Child. http://www.unicef.org/crc (accessed Aug 1, 2014)

16 Audcent T, MacDonnell H, Brenner J, Samson L. International child health (ICH) education in Canadian paediatric residency programs. Clin Invest Med 2007; 30 (suppl): S63-64 (abstr).

\title{
Patient safety after partial and total knee replacement
}

More than 90000 people in the UK had knee replacements in 2012, according to the National Joint Registry of England and Wales (NJR). ${ }^{1}$ The human cost of this expensive surgery is addressed in two articles in The Lancet $^{2,3}$ that question conclusions from the NJR, with major consequences for patient safety and the knee replacement industry.

The indications for knee replacement remain poorly defined: a patient with a small wear patch seen on MRI is given the same diagnosis as someone whose knee is severely damaged. Both are told they have osteoarthritis. International Classification of Diseases-10 labels osteoarthritis of the knee as gonarthrosis, M17.1, allowing no separation into compartments, and no classification of severity. So, despite being localised to one compartment in most people, ${ }^{4}$ because of poor diagnostic criteria, knee osteoarthritis can be validly approached with two different philosophies. Surgeons who deem knee osteoarthritis a disease excise the entire joint, thereby curing the disease and substituting a total knee replacement (TKR). Alternatively, those who deem it to be predictable wear do the smaller operation of partial, or unicompartmental knee replacement (UKR), relining the part that is worn, preserving the rest of the joint surfaces, and, importantly, the anterior cruciate ligament. In TKR, this important structure is routinely excised, which results in reduced ability to walk, ${ }^{5}$ explaining perhaps why TKR is less effective than is total hip replacement, ${ }^{6}$ and why life expectancy might also be affected.7 For patients undergoing either TKR or UKR, if done well, the probability is that this is the last operation that they will need in their lifetime, ${ }^{8}$ as results from hundreds of thousands of patients now enrolled into national joint registries around the world confirm.

Unlike tumour registries, which have strict diagnostic inclusion criteria and use death as an endpoint, joint registries are focused on the outcome of the device: anyone with any amount of joint damage can be admitted, only device-related surgical procedures are reported as failures, and death is counted as a success. Because arthrosis is closely related to ageing, the many patients who have died with no need for revision surgery stretch the use of so-called survivorship statistics when reporting the survival of the implant, not the patient. ${ }^{9}$

The NJR now has more than 500000 knee replacements registered, making it the world's largest registry, so conclusions from it should have a global impact. Set up to give warning of poorly performing devices, with operations leading to exchange of device as the main focus, the registry is now used to compare TKR with UKR. This focus can lead to perverse results: a joint replacement with a problem that can be fixed, curing the pain and restoring the patient's quality of life, is a failure owing to its revision, whereas a painful joint replacement that cannot be revised, condemning the patient to a lifetime of stiffness and pain, is recorded as a success in registry terms. ${ }^{10}$ Thus, TKRs are reported as successful despite the fact that $25 \%$ are no better or even worse after surgery. ${ }^{11}$ On the basis of revision rates alone, registry data continue to encourage surgeons to concentrate on TKR, and avoid UKR. ${ }^{12-15}$

The two Lancet papers look at the patients who have had knee replacements rather than their prostheses. Linda Hunt and colleagues ${ }^{2}$ undertook a multivariate analysis of 467779 cases from the NJR. They linked the national Hospital Episode Statistics (HES) with NJR data, in an observational study assessing 45-day mortality associated with knee arthroplasty to treat osteoarthritis. In their analysis, 1183 patients died within 45 days of surgery during the 8-year study period. Mortality decreased with time; from $0.37 \%$ in 2003 to $0.20 \%$ in 2011 , making knee surgery safer than hip replacement, which they reported on last year. ${ }^{9}$ They did, however, note a substantial difference in risk of perioperative death dependent on the type of procedure: the smaller, cheaper operation of
W

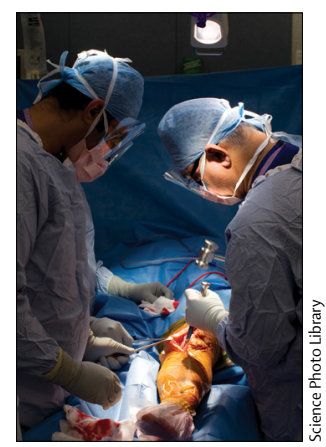

Published Online

July 8,2014

http://dx.doi.org/10.1016/ S0140-6736(14)60885-0

See Editorial page 1401

See Articles pages 1429 and 1437 
UKR was associated with substantially lower mortality than was TKR (hazard ratio [HR] 0.32, 95\% Cl 0.19-0.54). Despite this finding, Hunt and colleagues stop short of commending UKR. Perhaps this absent recommendation was to avoid conflict with the stream of registry publications promoting TKR over UKR, with revision as the only indicator of failure. ${ }^{13-17}$

Alexander Liddle and colleagues ${ }^{3}$ also link HES and NJR data. In addition to mortality, they look at all rates of reoperation, not just revision, and also complications, readmission to hospital, and length of hospital stay. A study group of more than 101330 matched cases was assembled with propensity score matching to include three TKRs for every UKR (25334 UKRs were matched to 75996 TKRs), ensuring the best possible use of data. They report early and late complications separately. Risk of early death after surgery was again significantly lower for UKR than for TKR at all timepoints (30 day: HR 0.23, 95\% Cl 0.11-0.50; 8 year: $0.85,0.79-0.92)$. To avoid one death by 4 years after surgery, the number needed to switch from TKR to UKR is 93, dropping to 62 at 8 years.

Death is not only a very firm and clinically important endpoint, but also a surrogate for more common risks of intraoperative complications, stroke, myocardial infarction, thromboembolism, blood transfusion, and admission to critical care-all much more common after TKR than after UKR. Implant-related complications resulting in operations occur later and were substantially more common after UKR (subhazard ratio [SHR] 2.12, 95\% Cl 1.99-2.26) at 8 years. ${ }^{3}$ These problems, which were mainly loosening and implant failure, were usually treated by a primary TKR. When the same problems of loosening or implant failure resulted in reoperation after TKR, they were often treated by larger so-called revision devices involving stems and augments. Infection, which is the most serious and costly local complication, was half as likely after UKR than after TKR in this large analysis $(0.50,0.38-0.66)$. In neither study was information available about thresholds for reoperation. By combining these datasets with outcome scores and costs, a formal cost-effectiveness analysis shows that UKR is a costeffective option, despite the revision rate. ${ }^{18}$

What can be drawn from these two large studies? When measured in terms of risk of perioperative death or serious morbidity, UKR is unequivocally safer than TKR. This simple message should be of great interest to patients and the clinical commissioning groups and insurers who pay for health care. This finding is at odds with the industry-funded NJR that suggests that UKR should be restricted, if not abandoned, for its high revision rate ${ }^{16}$ despite improved postoperative scores.

Arguments of this sort are not new to surgery. For women with operable breast cancer, for example, lumpectomy and radiotherapy offered substantial advantages, yet were met with fierce resistance from surgeons and centres promoting radical mastectomy. The strategy of radical mastectomy for all malignant breast disease was laid to rest 25 years ago with trial results showing no survival benefit over lumpectomy, despite a substantial reoperation rate for local recurrence in the conservative surgery group. ${ }^{19} \mathrm{~A}$ randomised trial of partial versus radical genuectomy (TKR has been described as internal amputation of the knee) reported at 5, 10, and 15 years showed that the smaller operation of UKR was not functionally inferior at any timepoint. ${ }^{20}$ Although in breast cancer survival rightly refers to the patient, and her breast, in the looking-glass of world of implant registries death is a success, and only implant revision counts as a failure. The fairly high mortality in the mainly older population who require knee replacement makes the use of survival statistics challenging when reporting on prostheses, not patients.

So what prevents the smaller, cheaper, and safer operation becoming adopted widely? UKR is a complex operation to learn, yet, in the UK, surgeons and hospitals are paid less for it by private insurers, with NHS reimbursement varying depending on what code is used. Today, many surgeons in the UK have agreed to have their activity and mortality statistics in the public domain as part of the government's focus on patient safety. The NJR goes further though. It reports surgeons to the chief executives of their hospitals, not for excessive mortality, strokes, myocardial infarctions, or infections, but for having a revision rate that is high for TKR, but could be normal for UKR perhaps simply because this small operation is rather easier to fix, if a problem arises. These two papers should provoke a review of knee arthroplasty by policy makers worldwide. Substantial public and private savings are possible: of the 90000 knee replacements reported in 2012 in England and Wales, only $8 \%$ were UKR. ${ }^{1}$ If only half of those eligible were offered the more conservative procedure of UKR, the NHS could save an estimated $£ 70$ million every 
year immediately on operative costs alone, ${ }^{18,21}$ and, on the basis of these two papers, there would be 170 fewer postoperative deaths annually, and many hundreds of fewer strokes, myocardial infarctions, and infections.

While perverse incentives remain in place, the TKR industry will continue to grow steadily encouraged by statistics based upon revision rates alone. With hundreds of lives and hundreds of millions of pounds at stake every year, a change in knee replacement strategy deserves consideration today, as it did with mastectomy 25 years ago.

\section{Justin P Cobb}

Section of Orthopaedics and MSk Lab, Imperial College London, Charing Cross Campus, London W6 8RP, UK

j.cobb@imperial.ac.uk

I am on the design team of a novel knee replacement at MatOrtho, and have received grants from MatOrtho, grants and personal fees from CeramTec, grants and personal fees from Stanmore Implants Worldwide, grants from Biomet, been on the speaker panel for Biomet, received grants from DePuy, been the principal investigator for the MHRA study of a novel hip design at JRI, and am cofounder, director, and minority shareholder of Embody, an Imperial start-up company developing patient-matched instruments for hip and knee arthroplasty. I have a patent on designs for knee implants for robotic implantation, and a patent on an anatomical design of acetabulum and femoral head pending.

Copyright $\odot$ Cobb. Open Access article distributed under the terms of CC BY.

1 National Joint Registry for England, Wales, and Northern Ireland. NJR 10th annual report 2013. Hemel Hempstead: National Joint Registry, 2013. http://www.njrcentre.org.uk/njrcentre/Portals/0/Documents/England/ Reports/10th_annual_report/NJR\%2010th\%20Annual\%20Report\%20 2013\%20B.pdf (accessed May 15, 2014).

2 Hunt LP, Ben-Shlomo Y, Clark EM, et al, on behalf of the National Joint Registry for England and Wales. 45-day mortality after 467779 knee replacements for osteoarthritis from the National Joint Registry for England and Wales: a retrospective observational study. Lancet 2014; published online July 8. http://dx.doi.org/10.1016/S0140-6736(14)60540-7.

3 Liddle AD, Judge A, Pandit H, Murray DW. Adverse outcomes after total and unicompartmental knee replacement in 101330 matched patients: a study of data from the National Joint Registry for England and Wales. Lancet 2014; published online July 8. http://dx.doi.org/10.1016/S0140-6736(14)60419-0.

4 Felson DT, Nevitt MC, Yang M, et al. A new approach yields high rates of radiographic progression in knee osteoarthritis. J Rheumatol 2008; 35: 2047-54.

5 Wiik AV, Manning V, Strachan RK, Amis AA, Cobb JP. Unicompartmental knee arthroplasty enables near normal gait at higher speeds, unlike total knee arthroplasty. J Arthroplasty 2013; 28: 176-78.
6 Ethgen O, Bruyere O, Richy F, Dardennes C, Reginster J-Y. Health-related quality of life in total hip and total knee arthroplasty. A qualitative and systematic review of the literature. J Bone Joint Surg Am 2004; 86: 963-74.

7 Studenski S, Perera S, Patel K, et al. Gait speed and survival in older adults. JAMA 2011; 305: 50-58.

8 Price AJ, Svard U. A second decade lifetable survival analysis of the Oxford unicompartmental knee arthroplasty. Clin Orthop Relat Res 2011; 469: 174-79.

9 Hunt LP, Ben-Shlomo Y, Clark EM, et al. 90-day mortality after 409096 total hip replacements for osteoarthritis, from the National Joint Registry for England and Wales: a retrospective analysis. Lancet 2013; 382: 1097-104.

10 Goodfellow J, O'Connor J, Murray D. A critique of revision rate as an outcome measure: re-interpretation of knee joint registry data. J Bone Joint Surg Br 2010; 92: 1628-31.

11 Noble PC, Gordon MJ, Weiss JM, Reddix RN, Conditt MA, Mathis KB. Does total knee replacement restore normal knee function? Clin Orthop Relat Res 2005; 431: 157-65.

12 Baker PN, Petheram T, Jameson SS, et al. Comparison of patient-reported outcome measures following total and unicondylar knee replacement. J Bone Joint Surg Br 2012; 94: 919-27.

13 Pearse A, Hooper G, Rothwell A, Frampton C. Survival and functional outcome after revision of a unicompartmental to a total knee replacement: the New Zealand National Joint Registry. J Bone Joint Surg Br 2010; 92: 508-12.

14 Knutson K, Lewold S, Robertsson O, Lidgren L. The Swedish knee arthroplasty register: a nation-wide study of 30,003 knees 1976-1992. Acta Orthop Scand 1994; 65: 375-86.

15 W-Dahl A, Robertsson O, Lidgren L, Miller L, Davidson D, Graves S. Unicompartmental knee arthroplasty in patients aged less than 65: combined data from the Australian and Swedish Knee Registries. Acta Orthop 2010; 81: 90-94.

16 Baker $\mathrm{P}$, Petheram T, Jameson $\mathrm{S}$, et al. Comparison of patient-reported outcome measures following total and unicondylar knee replacement. J Bone Joint Surg Br 2012; 94: 919-27.

17 Baker PN, Petheram T, Avery PJ, Gregg PJ, Deehan DJ. Revision for unexplained pain following unicompartmental and total knee replacement. J Bone Joint Surg Am 2012; 94: e126.

18 Andrews BA, Willis-Owen CA, Aqil A, CobbJP. A cost-utility analysis of knee arthroplasty using data from three national registries. American Academy of Orthopaedic Surgeons 2014 Annual Meeting Proceedings; New Orleans; March 11-15, 2014.

19 Fisher B, Redmond C, Fisher ER, et al. Ten-year results of a randomized clinical trial comparing radical mastectomy and total mastectomy with or without radiation. N EnglJ Med 1985; 312: 674-81.

20 Newman J, Pydisetty RV, Ackroyd C. Unicompartmental or total knee replacement: the 15-year results of a prospective randomised controlled trial. J Bone Joint Surg Br 2009; 91: 52-57.

21 Willis-Owen CA, Brust K, Alsop H, Miraldo M, Cobb JP. Unicondylar knee arthroplasty in the UK National Health Service: an analysis of candidacy, outcome and cost efficacy. Knee 2009; 16: 473-78.

\section{Do we need to know whether nitrous oxide harms patients?}

In The Lancet, Paul Myles and colleagues ${ }^{1}$ investigate the association between nitrous oxide exposure and cardiovascular complications such as non-fatal myocardial infarction, stroke, pulmonary embolism, cardiac arrest, and death, within 30 days of surgery, in patients with known or suspected coronary artery disease having major non-cardiac surgery under general anaesthesia. The rationale for this large, multicentre study, which involved more than 7000 patients from 45 centres, was the observation that short-term exposure to nitrous oxide led to significant increases in plasma homocysteine. ${ }^{2}$ Hyperhomocysteinaemia impairs arterial flow and has been associated with cardiovascular disease. ${ }^{3}$ The authors report that nitrous oxide did not increase
Published Online August 18, 2014 http://dx.doi.org/10.1016/ S0140-6736(14)61061-8 See Editorial page 1401 See Articles page 1446 